\title{
Resveratrol, a sirtuin 1 activator, increases IL-6 production by peripheral blood mononuclear cells of patients with knee osteoarthritis
}

Daniel Wendling ${ }^{1,2^{*}}$, Wasim Abbas ${ }^{2}$, Marie Godfrin-Valnet ${ }^{1}$, Xavier Guillot ${ }^{1}$, Kashif Aziz Khan ${ }^{2}$, Jean-Pierre Cedoz ${ }^{1}$, Lucile Baud ${ }^{2}$, Clément Prati ${ }^{1}$ and Georges Herbein ${ }^{2,3^{*}}$

\begin{abstract}
Background: Sirtuin 1 (Sirt1) is a nuclear enzyme from the class III histone deacetylases that modulates gene expression and is involved in bone and cartilage remodeling. The goal of our study was to evaluate Sirt1 activity in peripheral blood mononuclear cells in patients with osteoarthritis in comparison with control patients, and to determine the relationship between Sirt1 activity and production of TNFa, IL-6 and IL-8 by peripheral blood mononuclear cells after ex vivo treatment with resveratrol, a Sirt1 activator.

Results: A prospective study was performed to compare the activity of Sirt1 in patients with primary osteoarthritis of the knee (American College of Rheumatology criteria) with its activity in controls. Peripheral blood mononuclear cells were isolated from peripheral blood, and Sirt1 activity evaluated from cytoplasmic and nuclear compartments using a fluorometric assay. Culture supernatant levels of TNFa, IL-6, and IL-8 were quantified before and after resveratrol ex vivo treatment. Nineteen patients with symptomatic knee osteoarthritis (age $64 \pm 9$ years) and 18 controls (age $54 \pm 13$ years) were included. No differences were found in cytoplasmic or nuclear Sirt1 activity between patients and controls. After resveratrol treatment, no changes in TNFa or IL-8 levels were found, but a significant dose-dependent increase in IL-6 levels was demonstrated in patients with osteoarthritis, but not controls. Sirt1 activity did not correlate with clinical activity (Lequesne's index) or inflammation (erythrocyte sedimentation rate, C-reactive protein).
\end{abstract}

Conclusion: Sirt1 activity (cytoplasmic and nuclear) from peripheral blood mononuclear cells did not differ between patients with osteoarthritis and controls. Ex vivo treatment of peripheral blood mononuclear cells with resveratrol was associated with a dose-dependent increase in IL-6 levels only in patients with osteoarthritis.

Keywords: IL-6, Osteoarthritis, PBMCs, Resveratrol, Sirtuin 1

\section{Background}

Osteoarthritis (OA) is a common chronic age-related disease involving cartilage but also synovial membrane and subchondral bone. It has major functional and socioeconomic impacts. OA is a polygenic disease [1], but epigenetic effects are important mediators of OA biology [2], including DNA methylation and histone

\footnotetext{
* Correspondence: dwendling@chu-besancon.fr; georges.herbein@univfcomte.fr

'Department of Rheumatology, CHRU de Besançon, Boulevard Fleming, F-25030 Besançon, France

2EA 4266, Pathogens \& Inflammation Laboratory, SFR FED4234, Université de Franche-Comté, Besançon, France

Full list of author information is available at the end of the article
}

modifications. Among histone modifiers, two major classes are recognized; histone acetyl transferases and histone deacetylases (HDAC), with opposite effects [3]. HDACs are divided into four classes. Sirtuins belong to the class III HDACs. Seven types of sirtuins are known, with different molecular targets. Sirtuin 1 (Sirt1) is the most studied of the sirtuins with $\mathrm{p} 53$, NF- $\mathrm{kB}$ and PGC1 $\alpha$ among others as targets. Sirt1 modulates the expression of genes involved in the regulation of various biological processes (cell survival, apoptosis, gluconeogenesis, adipogenesis, lipolysis), and local and systemic inflammation, as well as in bone and cartilage remodeling $[4,5]$. In the cartilage, Sirt1 modulates chondrocyte

\section{Biomed Central}




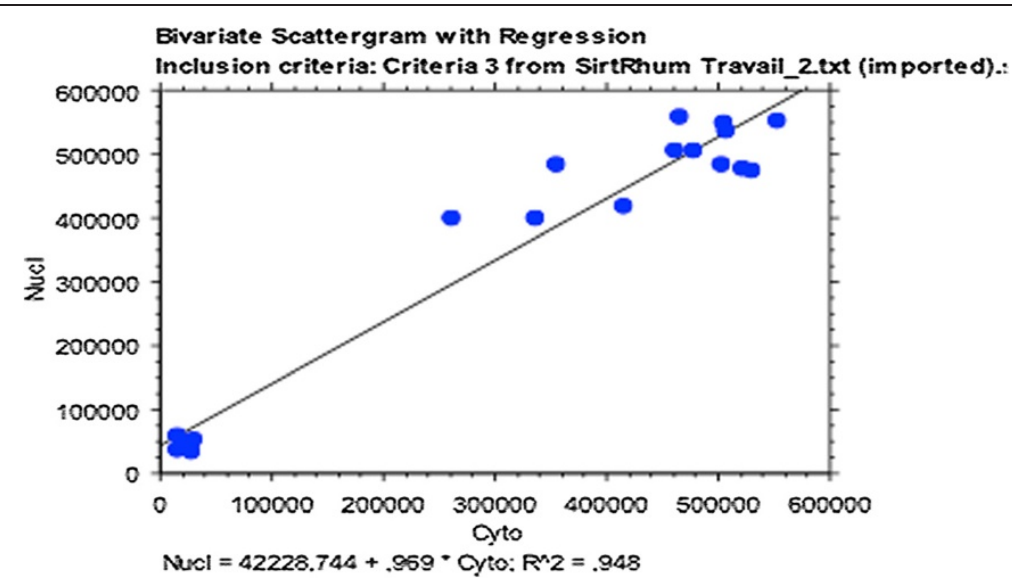

Figure 1 Correlation between nuclear and cytoplasmic Sirt1 activity in patients with osteoarthritis $\left(R^{2}=0.948\right)$.

apoptosis [6,7] and enhances survival of osteoarthritic chondrocytes [8], and thus may be implicated in the pathogenesis of OA [9]. This 'protective' role of Sirt1 is reduced by proinflammatory cytokines such as TNF $\alpha$, leading to inactivation of Sirt1 in human osteoarthritic chondrocytes [10]. Sirt1 may be activated by several compounds [11], including resveratrol [3]. Activation of Sirt1 by resveratrol has been demonstrated in articular chondrocytes [12], and resveratrol may have a positive effect on cartilage protection and apoptosis inhibition [13].

The hypothesis was that Sirt1 activity is reduced in patients with knee OA compared with healthy controls. This hypothesis was tested exploring an accessible body compartment, namely peripheral blood.

The main objective of the study was to evaluate nuclear and cytoplasmic Sirt1 activity in peripheral blood mononuclear cells (PBMCs) in patients with knee OA in comparison to control patients, via venous blood aspiration. The secondary objectives were to analyze the relationship between Sirt1 activity and production of mediators of inflammation and cytokines (TNF $\alpha$, IL-6, IL-8) by the cells after ex vivo treatment with a sirtuin activator, resveratrol.

\section{Results}

Nineteen patients with symptomatic primary knee OA (age $64 \pm 9$ years; mean Lequesne's index: 8.4; grade II or III of the Kellgren-Lawrence classification) and 18 controls (age $54 \pm 13$ years) were included. No differences were found between patients and controls in cytoplasmic $(P=0.8)$ or nuclear $(P=0.5)$ Sirt1 activity (Table 1$)$. There was no correlation between Sirt1 activity (nuclear and cytoplasmic) and biologic inflammation (erythrocyte sedimentation rate, C-reactive protein). Sirt1 activity did not correlate with clinical activity assessed by Lequesne's index $(P=0.8)$.

We found a correlation between cytoplasmic and nuclear Sirt1 activity in both populations (patients with OA and controls; $R^{2}=0.948$ ) (Figure 1). Sirt1 activity (nuclear and cytoplasmic) was correlated to baseline IL-6 $(P=0.002)$ and baseline TNF $\alpha(P=0.004)$ but not with IL-8 $(P=0.74)$ (Figure 2 and data not shown). In agreement with the upregulation of both Sirt1 protein expression and Sirt1 activity by resveratrol in several cell types $[14,15]$, we observed a similar increase of both Sirt1 protein expression and activity in PBMCs isolated from healthy donors (buffy coats) and treated with resveratrol (Figure 3). After resveratrol treatment, no changes in TNF $\alpha$ or IL-8 levels were found, but a significant dose-dependent increase in IL-6 levels in the supernatants of PBMCs cultured for $48 \mathrm{~h}$ was demonstrated in patients with OA $(P=0.02$; Figure 4$)$, but not in controls.

\section{Discussion}

The purpose of this study was to evaluate Sirt1 activity in cells from the peripheral blood compartment, which is more easily accessible than cartilage tissue.

Table 1 Values of biological parameters in patients with osteoarthritis and control participants

\begin{tabular}{|c|c|c|c|c|c|c|c|}
\hline $\begin{array}{l}\text { Mean } \\
\pm \text { SD }\end{array}$ & $\begin{array}{l}\text { Sirt1 nuclear } \\
\text { activity }\end{array}$ & $\begin{array}{c}\text { Sirt1 cytoplasmic } \\
\text { activity }\end{array}$ & $\begin{array}{l}\text { C-reactive protein } \\
(\mathrm{mg} / \mathrm{l})\end{array}$ & $\begin{array}{l}\text { Erythrocyte sedimentation rate } \\
\qquad(\mathrm{mm} / \mathrm{h})\end{array}$ & $\begin{array}{l}\text { TNFa } \\
\text { (pg/ml) }\end{array}$ & $\begin{array}{l}\mathrm{IL}-6(\mathrm{pg} / \\
\mathrm{ml})\end{array}$ & $\begin{array}{c}\mathrm{IL}-8 \\
(\mathrm{pg} / \mathrm{ml})\end{array}$ \\
\hline Control & $382,825 \pm 191,023$ & $352,907 \pm 195,317$ & $2.6 \pm 1.7$ & $3.0 \pm 14.5$ & $\begin{array}{c}29.0 \pm \\
27.2\end{array}$ & $8.6 \pm 5.0$ & $\begin{array}{l}1,083.3 \pm \\
771.6\end{array}$ \\
\hline Patients & $348,713 \pm 216,232$ & $316,314 \pm 217,313$ & $14.6 \pm 11.0$ & $4.5 \pm 2.7$ & $\begin{array}{c}23.7 \pm \\
21.4\end{array}$ & $5.1 \pm 3.6$ & $\begin{array}{c}1,148.7 \pm \\
2,173\end{array}$ \\
\hline$P$ & 0.5 & 0.8 & 0.0002 & 0.01 & 0.5 & 0.03 & 0.3 \\
\hline
\end{tabular}




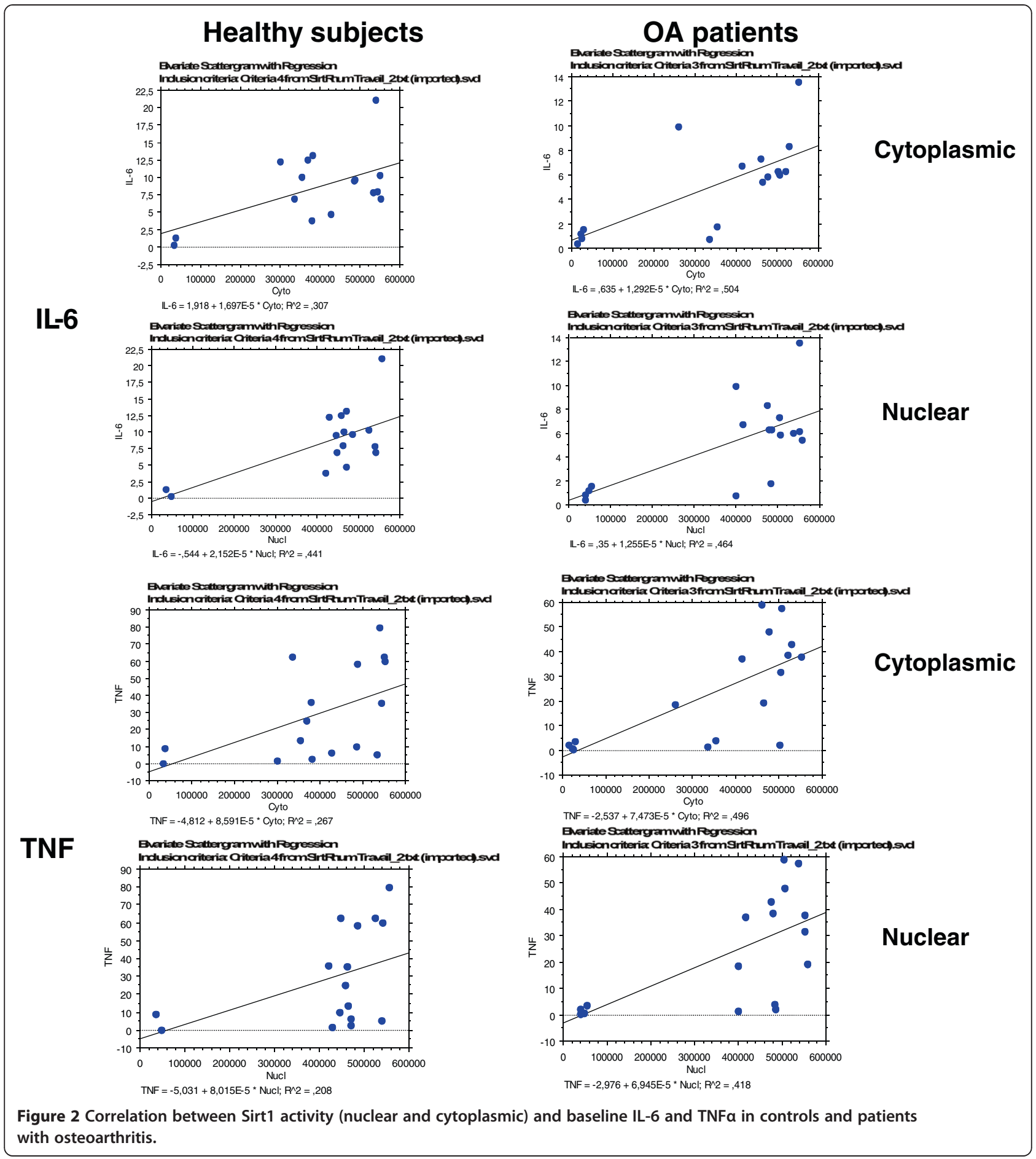

This study shows that Sirt1 evaluation on PBMCs drawn from peripheral blood is feasible, allowing an accessible cell subset for investigation. Moreover, this study demonstrates that Sirt1 activity is present, not only in the nuclear compartment but also in the cytoplasmic one, and both are correlated. Although the literature has previously shown mainly the nuclear activity of Sirt1 [3], at least two different mechanisms could account for its biological action. Sirt1 preferentially deacetylates lysine 9 of histone H3 and lysine 16 of histone H4 [16]. Additionally, Sirt1 interacts directly with the p65 subunit of NF-kB, leading to deacetylation at lysine 310 , culminating in decreased NF-kB-associated transcription [17]. Sirt1 deacetylates lysine 310 of RelA/p65 without affecting the acetylation status of other lysine residues [17]. Following resveratrol treatment, the localization of both Sirt1 and RelA/p65 

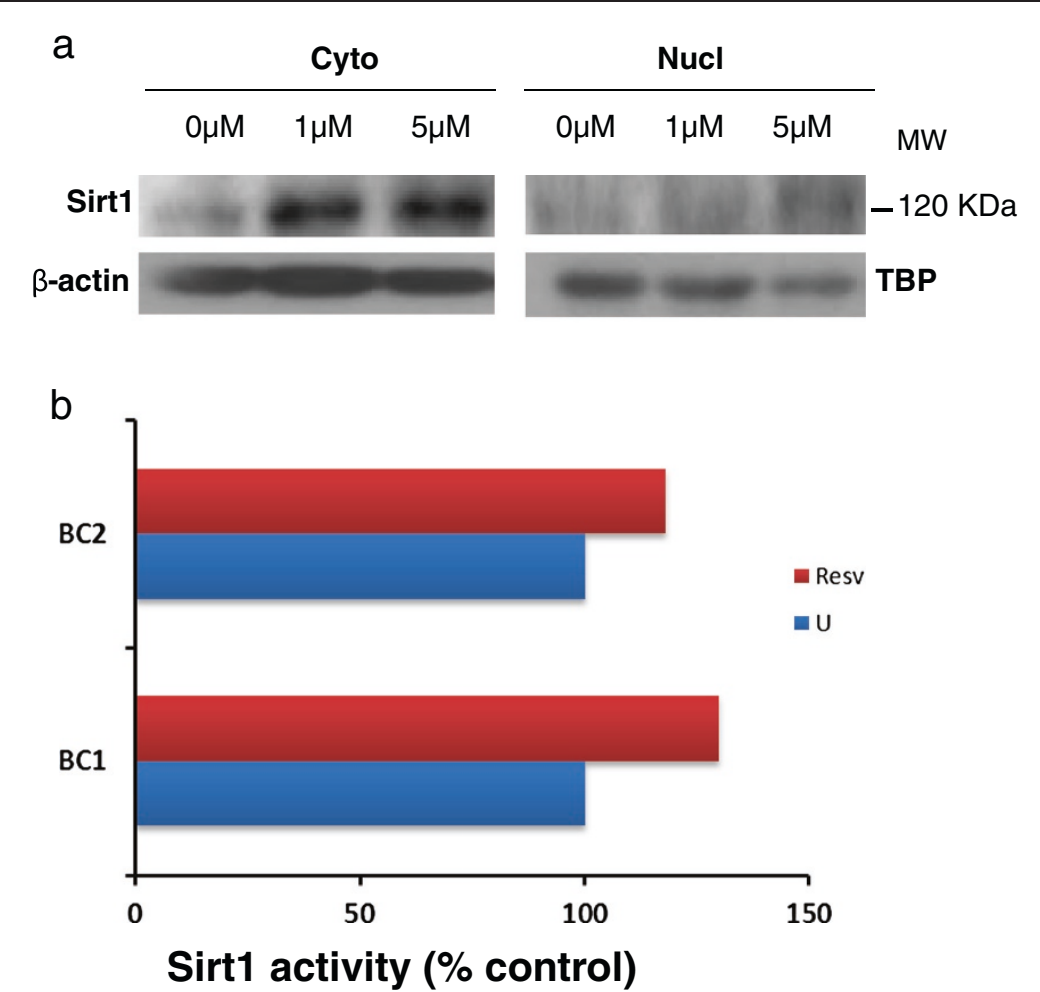

Figure 3 Effect of resveratrol on sirtuin 1 activity and expression in healthy controls. (a) Enhanced Sirt1 protein expression and (b) Sirt1 activity in peripheral blood mononuclear cells of healthy controls treated with resveratrol for 48 hours (at $1 \mu \mathrm{M}$ and $5 \mu \mathrm{M}$ for western blot and at $5 \mu \mathrm{M}$ for cytoplasmic Sirt1 activity). BC, buffy coat; TBP, TATA-binding protein.

proteins on the gene promoter suggests that Sirt1 may actively repress gene expression by deacetylating RelA/ p65 directly on chromatin [16]. In the case of NF-kB, the heterodimer composed of RelA/p65 and p50 proteins interacts also with HDAC1, 2 and 3 enzymes, making the regulation of NF- $\mathrm{KB}$-dependent genes even more complex [18]. Recently, the cathepsin B-mediated cleavage of Sirt1 by TNF $\alpha$ has been reported [10].

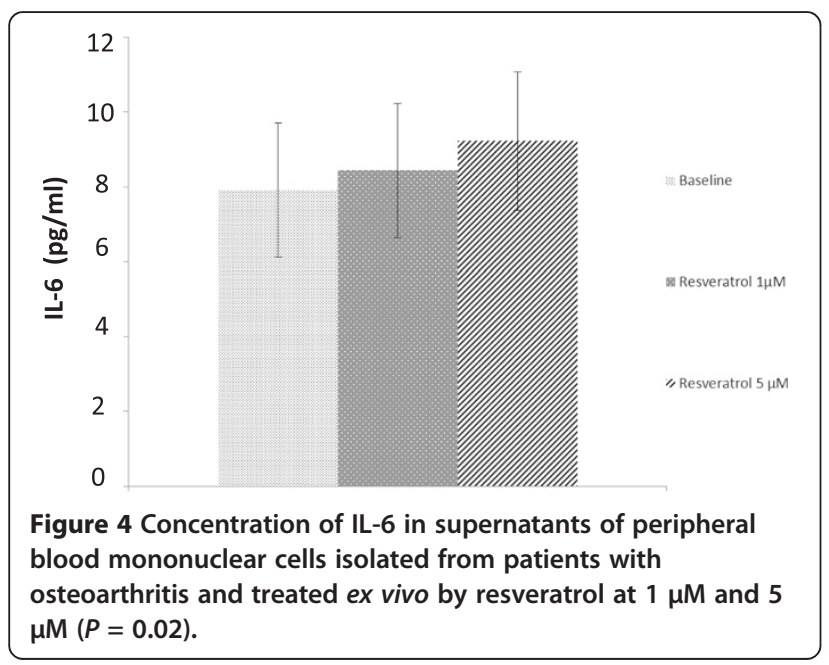

Interestingly, other proinflammatory cytokines participating in arthritis, including IL-6, have been reported to activate cathepsin B and therefore could also trigger the cleavage of Sirt1 [19].

It has been demonstrated that Sirt1 regulates apoptosisand cartilage-specific gene expression in human chondrocytes and mouse models [20]. Mice without Sirt1 activity are characterized by reduced levels of type II collagen, aggrecan, glycosaminoglycan, and elevated levels of matrix metalloproteinases 8, 9 and 13 in the cartilage, and elevated chondrocyte apoptosis. Normal cartilage homeostasis requires enzymatically active Sirt1 protein. Impaired Sirt1 activity may favor the development of OA.

An impairment of Sirt1 activity was hypothesized in patients with OA patients, however no difference was found between patients with OA and controls in regard to nuclear and cytoplasmic Sirt1 activity. The significantly younger age of the controls does not explain this result, since Sirt1 activity is supposed to decrease with age. Nevertheless, several other factors including diabetes and obesity have been reported to modulate Sirt1 activity [21]. No correlations with erythrocyte sedimentation rate or C-reactive protein were found in our study, but we found a correlation between Sirt1 and TNF $\alpha$ and IL-6. Moreover, after resveratrol treatment, a 
dose-dependent increase of IL-6 in the supernatants of PBMCs was found in patients with OA only, without a change in TNF $\alpha$ levels. Resveratrol enhances the deacetylase enzymatic activity of Sirt1 [22]. We observed that resveratrol at $1 \mu \mathrm{M}$ and $5 \mu \mathrm{M}$ increased the expression of Sirt1 protein in PBMCs isolated from buffy coats from healthy donors using western blotting (Figure 3a). Additionally, the activity of Sirt1 was increased in PBMCs treated with $5 \mu \mathrm{M}$ resveratrol (Figure $3 \mathrm{~b}$ ). In agreement with our data, other studies report the up-regulation of Sirt1 expression and Sirt1 activity in primary human endothelial cells or human HepG2 hepatocytes treated with $10 \mu \mathrm{M}$ resveratrol $[14,22]$. Resveratrol at $50 \mathrm{nM}$ inhibits TNF $\alpha$-induced inflammation measured by matrix metalloproteinase- 9 expression in 3T3/NIH cells [15]. Altogether, our data and those of others indicate a biological effect of resveratrol at concentrations used in our study ( 1 to $5 \mu \mathrm{M})$.

Recent reports indicate that Sirt1 can stimulate proinflammatory cytokine production $[23,24]$. In agreement with increased IL-6 production in response to resveratrol treatment in PBMCs, HDAC inhibitors inhibit IL-6 release by bone marrow-derived macrophages exposed to microbial products such as lipopolysaccharides (LPS) and heatkilled Escherichia coli and Staphylococcus aureus [25,26]. Sirtuin inhibition decreases the production of TNF $\alpha$, IL-6 and regulated upon activation normal $\mathrm{T}$ cell expressed and secreted (RANTES) in LPS-stimulated macrophages [23], suggesting that sirtuin activation may favor proinflammatory cytokine production by activated macrophages. In agreement with this hypothesis, inhibition of Sirt1 enzymatic activity reduces LPS-induced levels of TNF $\alpha$ in monocytes of patients with rheumatoid arthritis [24]. By contrast, other studies indicate that resveratrol inhibits TNF $\alpha$-induced inflammation via Sirt1 [15], and suppresses expression of TNF $\alpha$, IL-6 and IL-8 [27]. Sirt1 deacetylates the p65 subunit of NF- $\mathrm{KB}$ at lysine 310, attenuating NF- $\mathrm{kB}$ transcriptional activation, and thereby could decrease proinflammatory cytokine production. Altogether, Sirt1 activity and subsequent proinflammatory cytokine production may depend on the cell type involved (monocytes or macrophages, or PBMCs in peripheral blood compartment versus cells of the cartilage tissue) and on the activation state of the cell type studied (unstimulated cells versus LPS-activated cells).

Some findings of our study deserve to be highlighted. We were able to measure Sirt1 activity in the cytoplasmic compartment, and found a correlation with nuclear Sirt-1 activity. This demonstrates that Sirt1 activity may be assessed in PBMCs, allowing more easy access than cartilage tissue in humans, and thus could favor repetitive and sequential evaluations of treatments in the future. Additionally, because Sirt1 is involved in cartilage biology, it could be a major target for future therapies [28].

\section{Conclusion}

Sirt1 activity (cytoplasmic and nuclear) from PBMCs was not different between patients with $\mathrm{OA}$ and controls. Nevertheless, ex vivo treatment of PBMCs with resveratrol, a Sirt1 activator, was associated with increased IL-6 levels in a dose-dependent manner only in the patients with OA, suggesting that IL-6 expression could be specifically regulated via Sirt1 in OA. Importantly, Sirt1 activity may be assessed in PBMCs, in the nuclear as well as in the cytoplasmic compartment.

\section{Methods}

A prospective and comparative monocentric study was performed to compare the activity of Sirt1 in patients with OA and controls, after written informed consent. The protocol was approved by the local ethics committee (Comité de Protection des Personnes-Est 2). Inclusion criteria were: patients aged 18 to 80 years, with symptomatic primary knee OA defined according to the American College of Rheumatology criteria, with radiological grading (Kellgren-Lawrence classification over I). Exclusion criteria were: immunosuppressive drugs, diabetes or neurodegenerative disease. The control group consisted of healthy volunteers. Symptoms were quantified with Lequesne's algofunctional index for knee OA.

PBMCs were isolated by Ficoll gradient centrifugation. Blood from a patient or a healthy donor was diluted with equal amounts of PBS, overlaid on Ficoll medium (Eurobio, Les Ulis, France) and centrifuged at $900 \mathrm{X} \mathrm{g}$ for $30 \mathrm{~min}$ at $25^{\circ} \mathrm{C}$. The PBMC band was removed and washed twice with PBS. Cell count was determined by Malassez cytometry (Poly Labo, Strasbourg, France), and cells were resuspended in serum-free Roswell Park Memorial Institute medium 1640.

Isolation of nuclear and cytoplasmic extracts was performed as follows. After isolation, PBMCs were harvested and washed with wash buffer (10 mM HEPES ( $\mathrm{pH} 7.6)$, $10 \mathrm{mM} \mathrm{KCl}, 2 \mathrm{mM} \mathrm{MgCl}$, $1 \mathrm{mM}$ EDTA). Cell pellets were then incubated on ice with cytoplasmic isolation buffer (10 mM HEPES (pH 7.6), $10 \mathrm{mM} \mathrm{KCl,} 2 \mathrm{mM}$ $\mathrm{MgCl}_{2}, 1 \mathrm{mM}$ EDTA, 0.02\% Nonidet P-40). Cytoplasmic extracts were collected by centrifugation, and the nuclear pellets were washed twice in wash buffer, spun, and incubated for $15 \mathrm{~min}$ on ice with nuclear isolation buffer (20 mM HEPES (pH 7.6), $420 \mathrm{mM} \mathrm{NaCl}, 1.5 \mathrm{mM}$ $\mathrm{MgCl}_{2}, 0.2 \mathrm{mM}$ EDTA, 25\% glycerol). Supernatants containing nuclear extracts were collected by centrifugation and stored at $-80^{\circ} \mathrm{C}$. Protease inhibitors $(1 \mathrm{mM}$ DTT, $1 \mathrm{mM}$ PMSF, $1 \mu \mathrm{g} / \mathrm{ml}$ aprotinin, $1 \mu \mathrm{g} / \mathrm{ml}$ leupeptin, $1 \mu \mathrm{g} / \mathrm{ml}$ pepstatin) were added to all solutions. Protein concentration in nuclear and cytoplasmic extracts was determined by the Bradford method using a Bio-Photometer (Eppendorf, Hamburg, Germany). The purity of cytoplasmic and nuclear extracts was further confirmed by the 
quantification of the expression of $\beta$-actin, a cytoplasmic marker, and TATA-binding protein, a nuclear marker, using western-blotting (data not shown).

For western blot analysis, $10 \mu \mathrm{g}$ of cellular extracts were resolved on 10\% SDS-PAGE using a Mini-PROTEAN 3 Cell (Bio-Rad Laboratories, Hercules, CA, USA). The proteins were electrotransferred onto a polyvinylidene difluoridemembrane (Amersham Biosciences, Saclay, France) using Mini Trans-Blot Electrophoretic Transfer Cell (Bio-Rad Laboratories). The membranes were probed with primary antibodies followed by horseradish peroxidase-conjugated secondary immunoglobulin raised against the appropriate species; bands were detected using the ECL Plus kit (Amersham Biosciences). The primary antibodies used for western blot are as follows: rabbit anti-Sirt1 antibody (Cell Signaling Technology, Beverly, MA, USA); and mouse anti- $\beta$-actin antibody and mouse anti-TATA-binding protein antibody (Sigma-Aldrich, St. Louis, MO, USA). Horseradish peroxidaseconjugated secondary antibodies goat anti-rabbit (Santa Cruz Biotechnology Inc, Santa Cruz, CA, USA) and rabbit anti-mouse (DakoCytomation, Trappes, France) were used.

Sirt1 activity was evaluated from cytoplasmic and nuclear compartments using a fluorometric assay (SIRT1 fluorimetric kit, BML-AK-555; Enzo Life Sciences, Villeurbanne, France) at the 15 -min point. PBMC culture supernatant levels of TNF $\alpha$, IL- 6 and IL- 8 were quantified at 48 hours without and after resveratrol $(1 \mu \mathrm{M}$ and $5 \mu \mathrm{M})$ ex vivo treatment, with commercial kits (Quantikine Kits, R\&D Systems, Minneapolis, MN, USA), according to the manufacturer's recommendations. Statistical analysis was carried out using Wilcoxon and tests with significance set at $P<0.05$.

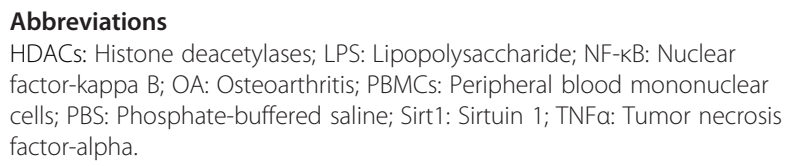
factor-kappa B; OA: Osteoarthritis; PBMCs: Peripheral blood mononuclear cells; PBS: Phosphate-buffered saline; Sirt1: Sirtuin 1; TNFa: Tumor necrosis factor-alpha.

\section{Competing interests}

$\mathrm{GH}$ is a member of the editorial board of Clinical Epigenetics. All other authors declare that they have no competing interests.

\section{Authors' contributions}

WA and KAK processed the blood samples, and prepared cytoplasmic and nuclear extracts; LB performed the sirtuin assay; MG-V, XG, JPC and CP enrolled the patients; DW and GH designed the experiments and wrote the manuscript. All authors read and approved this manuscript.

\section{Acknowledgement}

This work was supported by the Association Franc-Comtoise pour la Formation, la Recherche et l'Enseignement en Rhumatologie to DW; by grants from the University of Franche-Comté (UFC) and the Groupe de Recherche en Virologie de Franche-Comté to GH; WA and KAK are recipients of a doctoral scholarship from the Higher Education Commission, Pakistan. We thank Diasorin SA for its financial support.

\section{Author details}

'Department of Rheumatology, CHRU de Besançon, Boulevard Fleming, F-25030 Besançon, France. ${ }^{2}$ EA 4266, Pathogens \& Inflammation Laboratory, SFR FED4234, Université de Franche-Comté, Besançon, France. ${ }^{3}$ Department of Virology, CHRU de Besançon, 2 Place Saint-Jacques, F-25030 Besançon, France.

Received: 27 March 2013 Accepted: 3 July 2013

Published: 11 July 2013

\section{References}

1. Reynard LN, Loughlin J: Genetics and epigenetics of osteoarthritis. Maturitas 2012, 71:200-204.

2. Gabay O, Sanchez C: Epigenetics, sirtuins and osteoarthritis. Joint Bone Spine 2012, 79:570-573.

3. Herbein $G$, Wendling D: Histone deacetylases in viral infections. Clin Epigenetics 2010, 1:13-24.

4. Taylor DM, Maxwell MM, Luthi-Carter R, Kazantsev AG: Biological and potential therapeutic roles of sirtuin deacetylases. Cell Mol Life Sci 2008, 65:4000-4018

5. Zeng L, Chen R, Liang F, Tsuchiya H, Murai H, Nakahashi T, Iwai K, Takahashi T, Kanda T, Morimoto S: Silent information regulator, Sirtuin 1, and age-related diseases. Geriatr \& Gerontol Int 2009, 9:7-15.

6. Gabay O, Oppenhiemer H, Meir H, Zaal K, Sanchez C, Dvir-Ginzberg M: Increased apoptotic chondrocytes in articular cartilage from adult heterozygous SirT1 mice. Ann Rheum Dis 2012, 71:613-616.

7. Takayama K, Ishida K, Matsushita T, Fujita N, Hayashi S, Sasaki K, Tei K, Kubo S, Matsumoto T, Fujioka H, Kurosaka M, Kuroda R: SIRT1 regulation of apoptosis of human chondrocytes. Arthritis Rheum 2009, 60:2731-2740.

8. Gagarina V, Gabay O, Dvir-Ginzberg M, Lee EJ, Brady JK, Quon MJ, Hall DJ: SirT1 enhances survival of human osteoarthritic chondrocytes by repressing protein tyrosine phosphatase $1 \mathrm{~B}$ and activating the insulin-like growth factor receptor pathway. Arthritis Rheum 2010, 62:1383-1392.

9. Fujita N, Matsushita T, Ishida K, Kubo S, Matsumoto T, Takayama K, Kurosaka M, Kuroda R: Potential involvement of SIRT1 in the pathogenesis of osteoarthritis through the modulation of chondrocyte gene expressions. J Orthop Res 2011, 29:511-515.

10. Dvir-Ginzberg M, Gagarina V, Lee EJ, Booth R, Gabay O, Hall DJ: Tumor necrosis factor alpha-mediated cleavage and inactivation of SirT1 in human osteoarthritic chondrocytes. Arthritis Rheum 2011, 63:2363-2373.

11. Villalba JM, Alcain FJ: Sirtuin activators and inhibitors. Biofactors 2012, 38:349-359.

12. Lei $M$, Wang JG, Xiao DM, Fan M, Wang DP, Xiong JY, Chen Y, Ding Y, Liu SL: Resveratrol inhibits interleukin $1 \beta$-mediated inducible nitric oxide synthase expression in articular chondrocytes by activating SIRT1 and thereby suppressing nuclear factor-kB activity. Eur J Pharmacol 2012, 674:73-79.

13. Wang J, Gao JS, Chen JW, Li F, Tian J: Effect of resveratrol on cartilage protection and apoptosis inhibition in experimental osteoarthritis of rabbit. Rheumatol Int 2012, 32:1541-1548.

14. Csiszar A, Labinskyy N, Pinto JT, Ballabh P, Zhang H, Losonczy G, Pearson K, de Cabo R, Zhang C, Ungvari Z: Resveratrol induces mitochondrial biogenesis in endothelial cells. Am J Physiol Heart Circ Physiol 2009, 297:H13-H20.

15. Zhu X, Liu Q, Wang M, Liang M, Yang X, Xu X, Zou H, Qiu J: Activation of Sirt1 by resveratrol inhibits TNF- $a$ induced inflammation in fibroblasts. PLoS One 2011, 6:e27081.

16. Fusco S, Maulucci G, Pani G: Sirt1: def-eating senescence? Cell Cycle 2012, $11: 4135-4146$

17. Yeung F, Hoberg JE, Ramsey CS, Keller MD, Jones DR, Frye RA, Mayo MW: Modulation of NF-KB-dependent transcription and cell survival by the SIRT1 deacetylase. EMBO J 2004, 23:2369-2380.

18. Ashburner BP, Westerheide SD, Baldwin AS Jr: The p65 (RelA) subunit of $\mathrm{NF}-\mathrm{KB}$ interacts with the histone deacetylase (HDAC) corepressors $\mathrm{HDAC1}$ and HDAC2 to negatively regulate gene expression. Mol Cell Biol 2001, 21:7065-7077.

19. Chae HJ, Ha KC, Lee GY, Yang SK, Yun KJ, Kim EC, Kim SH, Chae SW, Kim HR: Interleukin-6 and cyclic AMP stimulate release of cathepsin B in human osteoblasts. Immunopharmacol Immunotoxicol 2007, 29:155-172. 
20. Gabay O, Sanchez C, Dvir-Ginzberg M, Gagarina V, Zaal KJ, Song Y, He XH, McBurney MW: Sirtuin 1 enzymatic activity is required for cartilage homeostasis in vivo in a mouse model. Arthritis Rheum 2013, 65:159-166.

21. Kotas ME, Gorecki MC, Gillum MP: Sirtuin-1 is a nutrient-dependent modulator of inflammation. Adipocyte 2013, 2:113-118.

22. Hou X, Xu S, Maitland-Toolan KA, Sato K, Jiang B, Ido Y, Lan F, Walsh $K$, Wierzbicki M, Verbeuren TJ, Cohen RA, Zang M: SIRT1 regulates hepatocyte lipid metabolism through activating AMP-activated protein kinase. J Biol Chem 2008, 283:20015-20026.

23. Fernandes CA, Fievez L, Neyrinck AM, Delzenne NM, Bureau F, Vanbever R: Sirtuin inhibition attenuates the production of inflammatory cytokines in lipopolysaccharide-stimulated macrophages. Biochem Biophys Res Commun 2012, 420:857-861.

24. Niederer F, Ospelt C, Brentano F, Hottiger MO, Gay RE, Gay S, Detmar M, Kyburz D: SIRT1 overexpression in the rheumatoid arthritis synovium contributes to proinflammatory cytokine production and apoptosis resistance. Ann Rheum Dis 2011, 70:1866-1873.

25. Roger T, Lugrin J, Le Roy D, Goy G, Mombelli M, Koessler T, Ding XC, Chanson AL, Reymond MK, Miconnet I, Schrenzel J, François P, Calandra T: Histone deacetylase inhibitors impair innate immune response to Toll-like receptor agonists and to infection. Blood 2011, 117:1205-1217.

26. Mombelli M, Lugrin J, Rubino I, Chanson AL, Giddey M, Calandra T, Roger T: Histone deacetylase inhibitors impair antibacterial defenses of macrophages. J Infect Dis 2011, 204:1367-1374.

27. Kang OH, Jang HJ, Chae HS, Oh YC, Choi JG, Lee YS, Kim JH, Kim YC, Sohn DH, Park H, Kwon DY: Anti-inflammatory mechanisms of resveratrol in activated HMC-1 cells: pivotal roles of NF-KB and MAPK. Pharmacol Res 2009, 59:330-337.

28. Dvir-Ginzberg M, Steinmeyer J: Towards elucidating the role of Sirt1 in osteoarthritis. Front Biosci 2013, 18:343-355.

doi:10.1186/1868-7083-5-10

Cite this article as: Wendling et al:: Resveratrol, a sirtuin 1 activator, increases IL-6 production by peripheral blood mononuclear cells of patients with knee osteoarthritis. Clinical Epigenetics 2013 5:10.

\section{Submit your next manuscript to BioMed Central and take full advantage of:}

- Convenient online submission

- Thorough peer review

- No space constraints or color figure charges

- Immediate publication on acceptance

- Inclusion in PubMed, CAS, Scopus and Google Scholar

- Research which is freely available for redistribution 